\title{
SMARTGLOVE: PROPOSTA DE DESENVOLVIMENTO DE UMA LUVA CAPAZ DE AFERIR A CARGA TRANSPORTADA
}

\author{
Michel Deivithy De Sousa Wanderley (UFCG) deivithymichel@gmail.com \\ Rayana Minervino Leite (UFCG) minervinorayana@gmail.com \\ Rodrigo Silva de Moura (UFCG) rodrigomouraep@gmail.com \\ Ravenna Lins Rodrigues (UFCG) ravennalinsrodrigues@ gmail.com \\ Daniel Augusto de Moura Pereira (UFCG) danielmoura@ufcg.edu.br
}

\section{Resumo}

As atividades de levantamento de cargas se enquadram nas atividades regulamentadas pelas Normas Regulamentadoras. A NR-17 no tópico 2.2, fala que nenhum operário deve transportar uma carga que possa comprometer a sua saúde. Já a Consolidação das Leis Trabalhistas no artigo 198 indica sobre o limite máximo de $60 \mathrm{~kg}$ para cargas a serem transportadas por homens adultos de maneira individual. Tomando como base a legislação supracitada, esse trabalho desenvolveu um Mockup de luva capaz de realizar a aferição do peso do objeto transportado pelo usuário, além de indicar maneira visual e sonora quando o mesmo ultrapassa o limite máximo de peso.

Palavras-Chaves: Biomecânica Ocupacional, Programação Embarcada, Levantamento de Cargas

\section{Introdução}

O advento da Indústria 4.0 e os avanços tecnológicos, têm gradativamente desafiado a indústria de fabricação tradicional, a automação de tarefas e o controle de dados e informações tem conquistado destaque nos processos industriais.

Mesmo com os avanços da tecnologia e da mecanização das tarefas, é comum encontrar diversas atividades que continuam sendo executadas, pelo homem, de forma manual. Em muitos casos, predominam o manuseio e a movimentação manual de cargas além dos limites tolerados (BATIZ, NUNES e LICEA, 2013). Dentre as atividades laborais, a carga e a descarga são situações clássicas e que não poupam o trabalhador do esforço físico intenso, implicando, comumente, em constrangimentos posturais, doenças ocupacionais e/ou acidentes (FISCHER; ALBERT; MCGARRY, 2012).

Apesar dos diversos meios de transporte mecanizados existentes, um grande número de insumos ainda necessita de algum tipo de transporte manual para chegar ao seu local de aplicação (CHAFFIN, ANDERSON e MARTIN, 2001). Tal fato, torna a automação de difícil 
implantação em trabalhos não estruturados, especialmente na indústria de serviços. A dúvida é se esta atividade está sendo realizada de forma correta, dentro dos limites normais de tolerância, ou se está sobrecarregando alguma parte do corpo (OLIVEIRA, et al.2014). Esta condição de dúvida quanto à forma em que ocorre o levantamento e ao limite máximo da carga é um fator de risco à saúde humana.

Nesse contexto, o uso de tecnologias digitais permite a integração de componentes inteligentes, e é possível pela adoção generalizada de tecnologias da informação e comunicação por organizações de manufatura (FUMAGALLI et al., 2017), e controle da produção a partir de sensores e equipamentos conectados em rede. Desta forma, o Arduino apresenta-se como relevante por tratar-se de uma plataforma de prototipagem eletrônica criada com o objetivo de permitir o desenvolvimento de controle de sistemas interativos, de baixo custo e com interface interativa (TRAJANO,2017).

Tomando como base este cenário, o presente estudo buscou desenvolver um mockup, em formato de luva, capaz de medir o peso de objetos, manuseados pelo usuário. Além de indicar quando o objeto ultrapassar o peso limite pré-estabelecido para o porte do usuário.

\section{Referencial Teórico}

\subsection{Normas Regulamentadoras (NRs)}

Segundo o Governo Federal (2020a). As Normas Regulamentadoras são regras e obrigações que buscam complementar a Consolidação das Leis do Trabalho (CLT) e que devem ser cumpridas a fim de garantir a segurança e a saúde para os empregadores e funcionários, prevenindo assim a ocorrência de problemas de saúde e acidentes de trabalho.

A Norma Regulamentadora 17 (NR-17) trata das disposições ergonômicas do ecossistema laboral, de acordo com o Governo Federal (2020b), a mesma é responsável por estabelecer os parâmetros psicológicos e fisiológicos do ambiente de trabalho, por meio da adaptação dos postos de trabalho, a fim de garantir conforto, desempenho e segurança. Para tanto, sua função é regulamentar o cumprimento dos artigos 175,176,178,198,199 da CLT (GOVERNO FEDERAL, 2020b). O tópico 2.2 da NR-17 complementa o artigo 198 da CLT, tratando das normas de transporte individual de cargas 


\subsection{Consolidação Das Leis Trabalhistas (CLT)}

Criada em 1943 a Consolidação das Leis Trabalhistas (CLT), Lei $\mathrm{n}^{\circ}$ 5452, surgiu para garantir ao trabalhador, em forma de norma, uma proteção contra condições inadequadas de trabalho, sendo de acordo com Wladimir Pereira, especialista em direito do trabalho, a única garantia de um mínimo de dignidade ao trabalhador (JUSBRASIL, 2015).

Dentre essas condições de trabalho submetidas pela CLT, os artigos de número 198 (Art.198), designa o limite de peso para o transporte de cargas entre homens adultos. Enfatizando o limite de peso estabelecido entre homens adultos, de acordo com a Lei de $n^{\circ} 5452$, Art 198, temos que:

“Art. 198 - É de $60 \mathrm{~kg}$ (sessenta quilogramas) o peso máximo que um empregado pode remover individualmente, ressalvadas as disposições especiais relativas ao trabalho do menor e da mulher.(Redação dada pela Lei no 6.514, de 22.12.1977)" (GOV,1977)

\subsection{Biomecânica Ocupacional}

A biomecânica ocupacional examina as relações entre o trabalho e o homem sob o ponto de vista dos movimentos músculo-esqueléticos envolvidos e as suas consequências (KAKAZU, 2016) durante a jornada de trabalho.

Os problemas mais presentes nos campos de trabalho, geralmente, são decorrentes dos traumas por esforços excessivos. Os quais são responsáveis pela maior parte do afastamento dos trabalhadores, em consequência das doenças e lesões no sistema músculo-esquelético. Enquanto os acidentes por traumas de impactos têm uma menor frequência nos postos laborais. Os resultados desses esforços pela estrutura esquelética podem causar doenças ocupacionais como lesões, DORTS, lombalgias, dores musculares, entre outras. (MÁSCULO; VIDAL, 2011).

De acordo com Kroemer e Grandjean (2005), o manuseio de cargas gera desgaste na coluna, em especial nos discos invertebrados da região lombar, degenerando-os, o que pode ocasionar a redução da mobilidade e vitalidade do trabalhador. Nadon et al. (2016) destacam que o manuseio de cargas, especialmente levantamento e abaixamento, contribui para lesões nos ombros. Neste caso, fadiga, esforço repetitivo, sobrecarga de peso e postura inadequada aumentam a incidência de lesões nos ombros. 
Ilda e Buarque (2016), abordam que através da biomecânica ocupacional é possível analisar as posturas, aplicação de forças e quantificar as cargas mecânicas, e com isso gerar um diagnóstico sobre o impacto no sistema osteomuscular. Assim, com esta análise e diagnóstico torna-se possível a geração de condições adequadas de postos de trabalho, contribuindo para a redução de distúrbios osteomusculares, assim como maior produtividade e rendimento.

\section{Materiais e Métodos}

O presente artigo se trata de uma pesquisa aplicada, descritiva e qualitativa. Inicialmente foi realizada uma revisão bibliográfica para adquirir embasamento teórico, onde principalmente o art. 198 da CLT, juntamente com a NR 17, especialmente o tópico 2.2, foram utilizadas como guia para o desdobramento do projeto. O Mockup foi desenvolvido utilizando a plataforma de prototipagem arduino, devido a sua popularidade e variedade de sensores e componentes, assim facilitando a compra e programação dos materiais utilizados.

Figura 2 - Mapa mental do fluxo metodológico

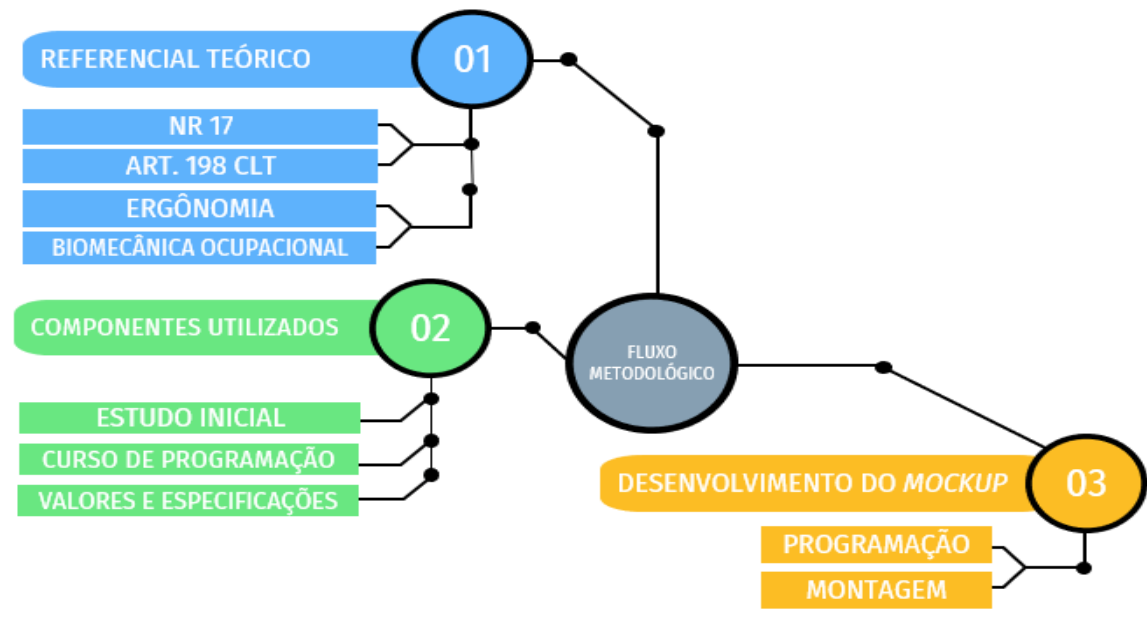

Fonte: Autores (2021)

Para fins de melhor entendimento, a Figura 2 representa o mapa mental do processo metodológico utilizado no desenvolvimento do projeto. Tendo em vista os conhecimentos limitados acerca dos componentes necessários, as funcionalidades de cada um deles foi estudada por meio de cursos de programação em Arduino.

A montagem e programação da parte lógica foi feita de maneira progressiva, ou seja, pouco a pouco cada componente foi sendo implementado na luva, tanto fisicamente quanto virtualmente, utilizando bibliotecas disponíveis na internet. Os componentes utilizados na luva 
foram instalados nas protoboards, que foram divididos em 2 módulos, o modulo da mão 1 (Célula de carga, Conversor HX 711, Painel OLED, Conjunto de Leds, Buzzer, Receptor RF) e o módulo da mão 2 (Célula de carga, Conversor HX 711, Transmissor RF). Cada um dos módulos foi acoplado as luvas por meio de velcros instalados no punho da luva e nas protoboards, exceto a célula de carga que foi instalada na palma de cada uma das luvas.

\section{Resultados}

\subsection{Introdução ao Mockup}

O presente projeto, por meio das técnicas e métodos supracitados, conseguiu atender às demandas da proposta inicial, sendo possível por meio do Arduino e seus componentes, construir uma luva capaz de aferir o peso de um objeto de até cem quilogramas, além de alertar o usuário caso o ultrapasse o peso limite predeterminado. O Mockup em seu modelo final, é mostrado na Figura 3 a seguir.

Figura 3- Mockup finalizado

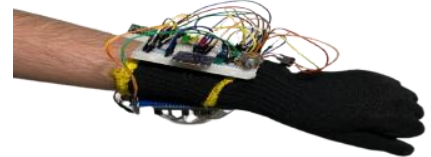

Figura 3 a)

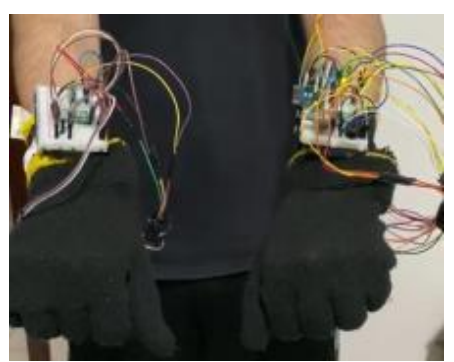

Figura 3 b)

Fonte: Autoria Própria

A Figura acima mostra o Mockup montado e vestido. $\mathrm{O}$ instrumento se destaca pela sua capacidade, podendo medir objetos de até 100 quilogramas. Além disso, o conforto oferecido aliado a autonomia concedida pelas baterias, possibilita uma boa usabilidade e estabilidade mesmo não estando conectado ao software de programação, provando sua viabilidade técnica.

\subsection{Programação e funcionamento dos componentes}

A partir da linguagem de programação do arduino, foi desenvolvido a lógica de processamento para as luvas. A Figura 4 apresenta o fluxograma do processamento da luva onde vai a maior parte dos componentes (Luva 1). Cada uma das luvas utiliza sua respectiva célula de carga (CG) para fazer a aferição do peso do objeto carregado pelo operador. 
A luva 1 recebe o valor medido pela luva 2 por meio de comunicação de radiofrequência e soma com o valor obtido da sua própria CG. A soma é mostrada no Painel OLED (Figura 5), bem como o peso definido pelo usuário, e peso máximo medido nos últimos segundos. Caso esse valor ultrapasse o peso definido pelo operador por meio do potenciômetro, a luva emitirá diversos sinais de alerta para avisar que a carga está acima do limite.

Figura 4 - Fluxograma do processamento da luva

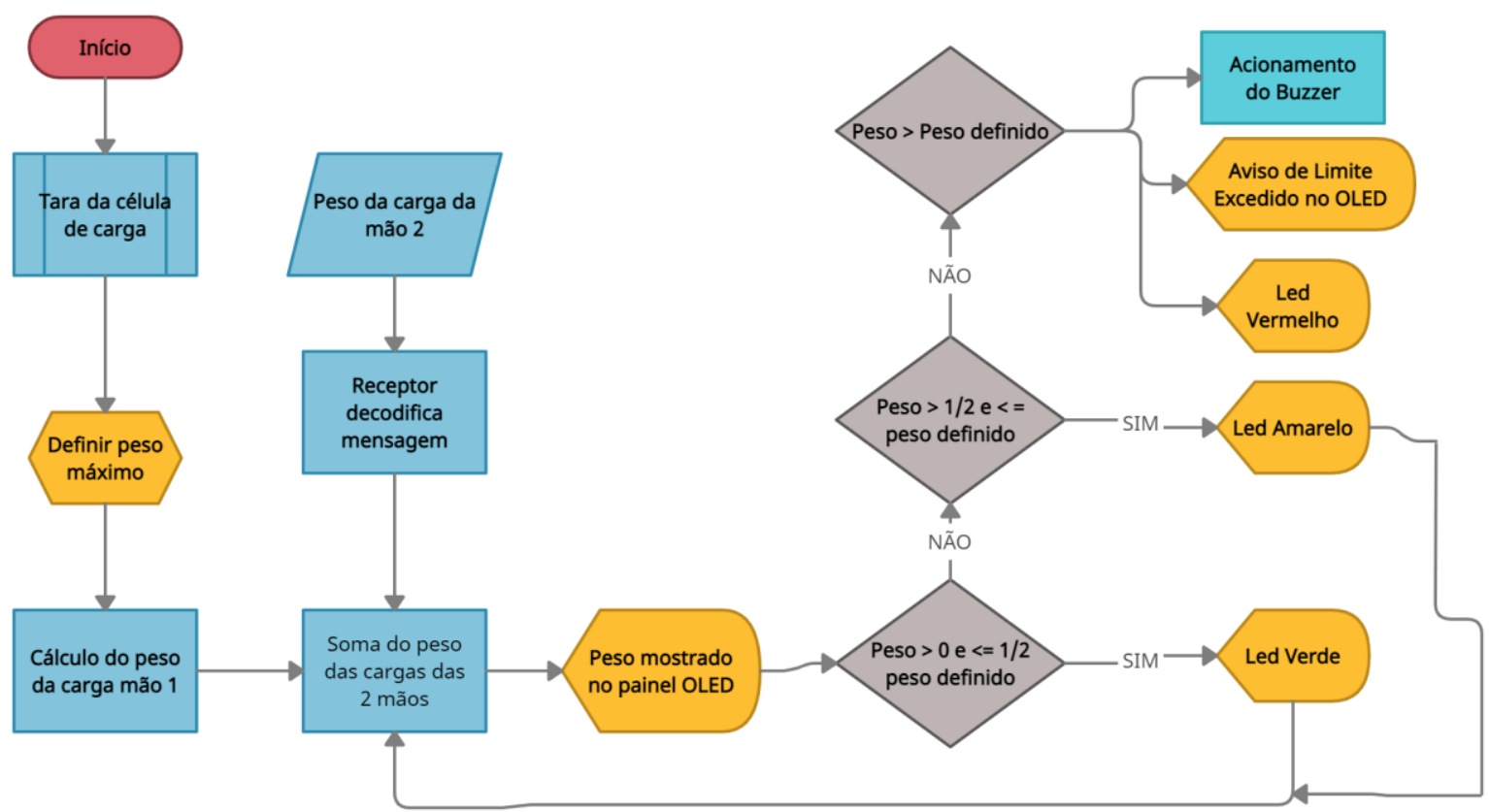

Fonte: Autores (2021)

Considerando a nossa base teórica, houve uma preocupação em desenvolver um produto que pudesse oferecer segurança ao usuário, por meio do emprego de sinais visuais de intensidade a partir de um conjunto de leds instalados, sinais sonoros do buzzer, e imagem de limite excedido no painel OLED (Figura 5), visando passar a maior quantidade possível de informações aos seus principais canais sensoriais. 
Figura 5 - Painel OLED e potenciômetro

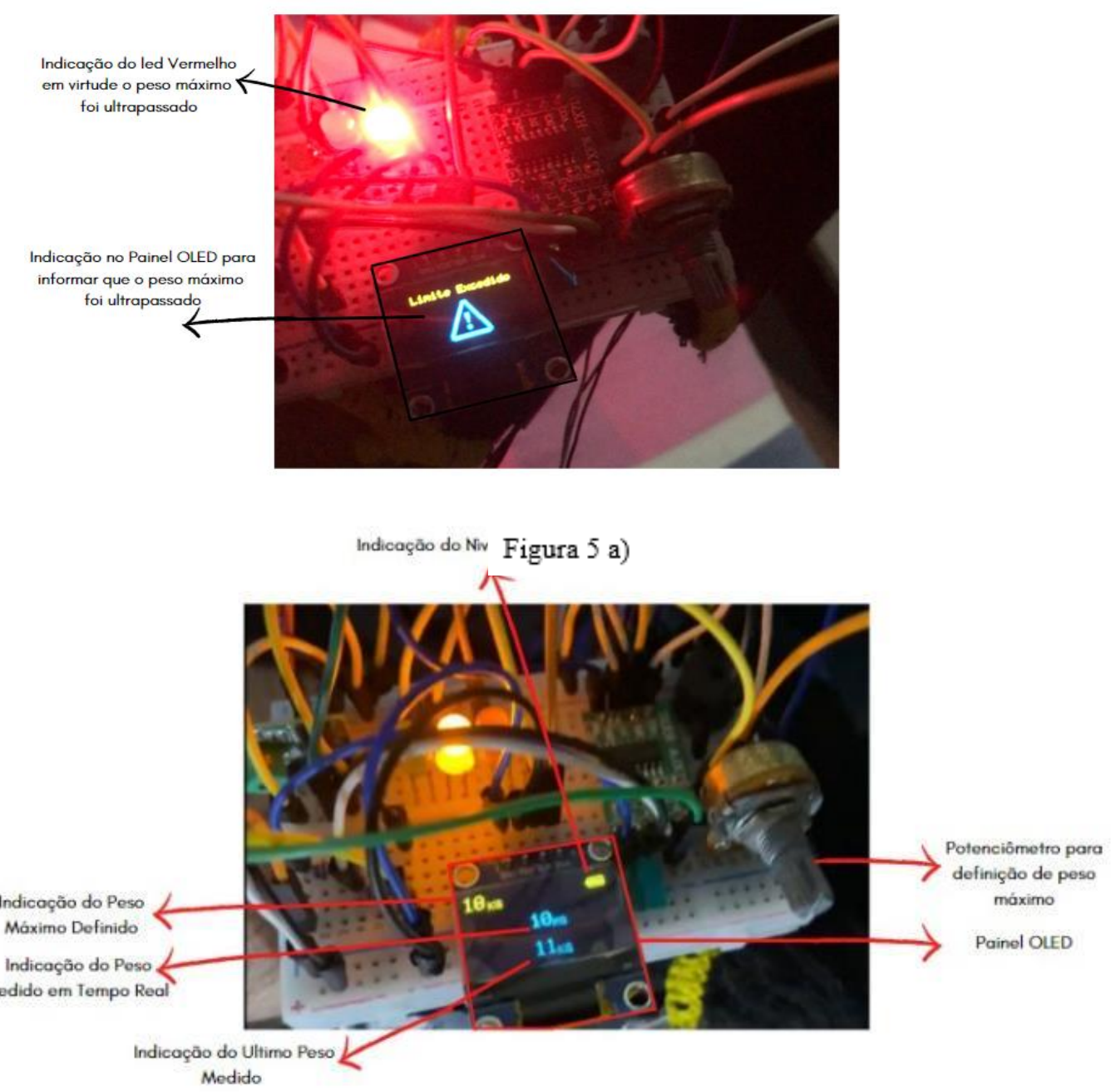

Figura 5 b)

Fonte: Autores (2021)

O comportamento desses sinais depende de duas entradas, a primeira é o peso definido pelo usuário por meio do potenciômetro e a segunda é o peso medido pela luva por meio da célula de carga. O microcontrolador do arduino é responsável por processar esses dados e realizar o acionamento de cada componente a partir da lógica de programação previamente definida (Figura 6). 
Figura 6 - Sinais visuais emitidos pela SmartGlove

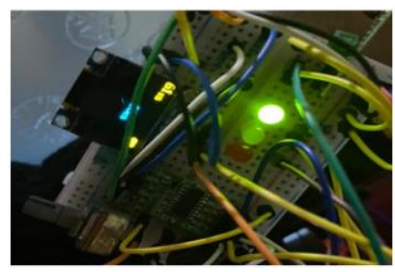

a)

Figura 6 a)

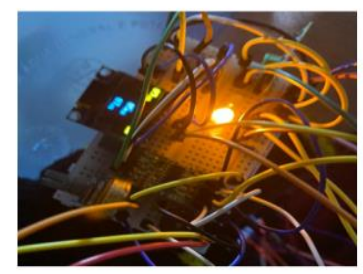

b)

Figura 6 b)

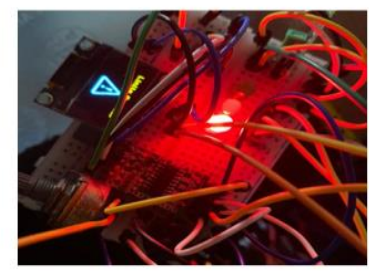

c)

Figura $6 \mathrm{c}$ )

Fontes: Autores (2021)

Enquanto a) o peso da carga não ultrapassar os $30 \mathrm{~kg}$, um led verde ficará aceso, representando um funcionamento. b) A carga fique entre 30 e $60 \mathrm{~kg}$, apenas o led amarelo ficará aceso, representando um estado de alerta. c) Já quando a carga ultrapassar os $60 \mathrm{~kg}$, apenas o led vermelho ficará aceso e soará um alarme para alertar o usuário que aquela carga não deve ser transportada de maneira individual.

\subsection{Manual do usuário}

Visando a importância de saber utilizar a luva e entender seu funcionamento, tendo em vista que existe todo um procedimento padrão, foi efetuada a construção de um manual, dado que a luva foi projetada de uma forma em que suas partes fossem desmontadas.

Figura 7 - QR code do Manual

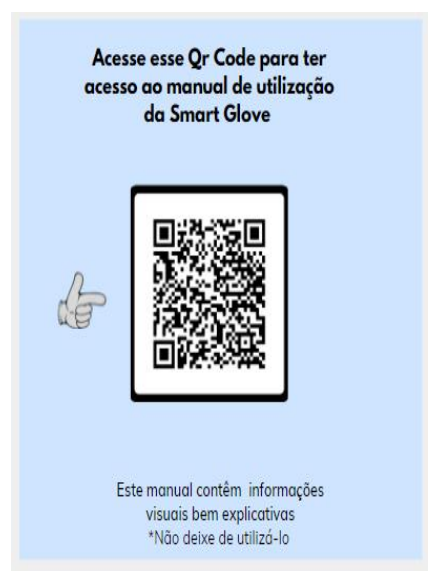

Fonte: Autores (2021)

O manual foi construído de maneira ilustrativa, a fim de um garantir melhor entendimento do usuário, independentemente do seu nível de escolaridade. A partir dele é possível ver o passo a 
passo da montagem e conFiguração da luva, desde o posicionamento das luvas e braceletes até a definição do peso máximo. A Figura 7 mostra o QR code utilizado para acesso à luva.

\section{Considerações finais}

O desenvolvimento do protótipo foi bem sucedido, uma vez que foi possível atingir os objetivos propostos pelo estudo. A SmartGlove é viável e funcional, uma vez que consegue determinar o valor da carga transportada pelo usuário com precisão, transmitindo informações de maneira visual e auditiva, garantindo segurança e saúde ao colaborador.

Existem algumas dificuldades técnicas no projeto e que podem ser indicadas como pontos de melhoria. A célula de carga utilizada tem pouca exatidão e apresenta instabilidade em alguns casos, sendo necessário reiniciar o sistema. Além disso, a utilização de transmissores de radiofrequência acaba limitando a velocidade de processamento do conjunto de luvas.

\section{Referências}

BRASIL. Decreto-lei n ${ }^{\circ} 5.452$, de 1 de maio de 1943. Aprova a consolidação das leis do trabalho. DA PREVENÇÃO DA FADIGA: coletânea de legislação: edição federal,seção XIV, 1943.

BRASIL. Decreto-lei no ${ }^{\circ}$ 5.452, de 1 de maio de 1943. Aprova a consolidação das leis do trabalho. DA PREVENÇÃO DA FADIGA: coletânea de legislação: edição federal, V.1, Capítulo V, seção XIV, 1943.

BRASIL. Decreto-lei no 5.452, de 1 de maio de 1943. Aprova a consolidação das leis do trabalho. DOS MÉTODOS E LOCAIS DE TRABALHO: coletânea de legislação: edição federal, V.3, Capítulo II, seção IV, 1943.

Fundação Brasileira de Ergonomia - ABERGO - A certificação do ergonomista brasileiro. Editorial do Boletim 1/2000, Associação Brasileira de Ergonomia.

IIDA, I. Ergonomia: Projeto e produção. 2. ed. rev. e ampl. São Paulo: Edgard Blücher, 2005.

GOVERNO FEDERAL (Brasil). Secretaria do Trabalho. Normas Regulamentadoras - NR., 2020A.

GOVERNO FEDERAL (Brasil). Secretaria do Trabalho. Norma Regulamentadora No. 17 (NR-17), 2020B.

TONI, Wladimir. A importância da CLT após tantas décadas. JusBrasil, 2015. Disponível em: < https://wptoni.jusbrasil.com.br/artigos/227643732/a-importancia-da-clt-apos-tantas-decadas >. Acesso em: 25 de maio de 2021.

IIDA, Itiro.: BUARQUE, Lia.: ERGONOMIA: Projeto e Produção. 3. Ed - São Paulo: Blucher, 2016. 
KAKAZU, Milleni Harumi. Análise da biomecânica ocupacional em uma confecção têxtil. 2016. Trabalho de Conclusão de Curso. Universidade Tecnológica Federal do Paraná.

KROEMER, K. H. E.; GRANDJEAN, E. Manual de Ergonomia: adaptando o trabalho ao homem. Trad. Lia Buarque de Macedo Guimarães. 5. ed. Porto Alegre: Bookman, 2005

MÁSCULO, F. S.; VIDAL, M. C. Ergonomia: Trabalho adequado e eficiente. Rio de Janeiro: Ed Elsevier Ltda, 2011.

NADON, A.; VIDT, M.; CHOW, A.; DICKERSON, C.The spatial dependency of shoulder muscular demands during upward and downward exertions. Ergonomics, vol. 59, issue 10, pp. 1294 - 1306, 2016.

BATIZ, Eduardo Concepción; NUNES, Jandira Izabel da Silva; LICEA, Olga Elena Anzardo. Prevalência dos sintomas musculoesqueléticos em movimentadores de mercadorias com carga. Production, v. 23, n. 1, p. 168-177, 2013.

CHAFFIN, B., ANDERSON, G. B. J., MARTIN, B. J. Biomecânica ocupacional. Belo Horizonte: Ergo, 2001. CLT, Consolidação das Leis Trabalhistas - Lei 6.514 de 22 de dezembro de 1977.

FISCHER, S. L.; ALBERT, W. J.; MCGARRY, T. Visual perception of fatigued lifting actions. Human Movement Science, v. 31, p. 1552-1559, 2012.

FUMAGALLI, Luca et al. Simulation-supported framework for job shop scheduling with genetic algorithm. In: 22nd Summer School" Francesco Turco"-Industrial Systems Engineering 2017. AIDI-Italian Association of Industrial Operations Professors, 2017. p. 271-278.

OLIVEIRA, D. R. Et Al. Padrão De Ativação Dos Músculos Eretores Da Coluna Durante O Levantamento De Cargas Em Mulheres Com Método De Normalização Adaptativa De Eletromiografia. Xxiv Congresso Brasileiro De Engenharia Biomédica - Cbeb 2014. TRAJANO, Tarcisio Oliveira et al. Desenvolvimento de um sistema automatizado para medir a variação de massa na câmara de secagem de um secador solar de frutas. 2017. 